\title{
The Vagina Monologues in a Chinese Context: Discussing the Value of the Localized Adaptations
}

\author{
Yuxuan Zhang ${ }^{1}$ \\ ${ }^{1}$ Northfield Mount Hermon School, USA \\ Correspondence: Yuxuan Zhang, Northfield Mount Hermon School, USA. E-mail: yzhang21@nmhschool.org
}

Received: September 14, 2020 Accepted: October 20, 2020 Online Published: November 17, 2020

doi:10.5539/ells.v10n4p47 URL: https://doi.org/10.5539/ells.v10n4p47

\begin{abstract}
The silence around female genitalia and sexuality is a prevalent phenomenon with grave implications. Eve Ensler, an American playwright, wrote the famous Vagina Monologues to combat such issues and aim to end violence against women. While Ensler's play is popular on a global scale, the localized versions inspired by Ensler are also emerging in various regions. A Chinese feminist organization, The Vagina Project, has created their own script and organized several localized performances in the past few years. A close analysis of one of the scripts written by the Vagina Project demonstrates that the localized versions of The Vagina Monologues, though less paid attention to, are effective in creating connections with the audience. Being attuned to the regional feminist differences allows the play to be more powerful and thoughtful when presented to the audience.
\end{abstract}

Keywords: The Vagina Monologues, China, vagina, virginity, sex, feminism, Eve Ensler

\section{Introduction}

Roughly two years ago, my classmates and I conducted a class activity, where we listed slangs for female genitals and male genitals. While the list for male genitals went on and on, the list for female genitals stopped at five terms. This activity might not be completely representative of the general situation because some students were international and there were more males in the class. However, our class still concluded that female genitals are not only less discussed, their slangs also lack precision and specificity, compared with their male counterparts. A recent study confirmed our conclusions, further suggesting that men were able to produce more terms than women, for both male and female genitalia. This indicates that men are more comfortable conversing about sexual issues (Note 1). The same study also asserted that a lack of precision in female genitalia slang implies a lack of attention to the details of female genitalia and their functions (Note 2).

In addition, public discourse around female genitals has always been largely restricted. Back in 2012, television networks in the US did not allow advertisements to mention the word "vagina", even if it is what the product was made for, such as tampons and douches (Note 3). In fact, the phenomenon of discomfort talking about vaginas is not limited to the United States. In 2015, a survey of 1000 British women "found that two-thirds of those ages 18 to 24 who participated said they'd be too embarrassed to use the word 'vagina' at the doc's office" (Note 4). In China, the whole subject of female sexuality is deemed unfit for public conversations, not to mention openly using the word "vagina". "On Chinese TV, advertisements for feminine hygiene products are banned during prime time and lunchtime" (Note 5), for China's media regulator found such commercials "disgusting" (Note 6). Back in 2004, China Central Television even had obstacles broadcasting the popular American sitcom Friends, "because sex is mentioned too many times, officials said" (Note 7). To sum up, an abundance of evidence suggests that there is a globally existing silence around naming and discussing female sexuality in both private and public discourses. The silence can have severe consequences. In the healthcare context, women's lack of transparent communication with gynecologists can lead to inaccurate diagnoses and treatment. In the feminist perspective, breaking the silence around female sexuality is viewed as a first step toward combatting the crime of rape (Note 8).

Eve Ensler, an American playwright and feminist activist, recognized this issue and produced The Vagina Monologues, which then turned into a theatrical phenomenon. By dealing with themes such as sexual experience, female genital mutilation, vaginal care, menstruation, masturbation, orgasm, sex work, and rape, the play combats the silence around female sexuality and gives women a voice to claim their bodies.

In this paper, I address the following research questions: How do the localized versions of The Vagina Monologues 
break the silence around female sexuality? What new knowledge comes from breaking the silence? In order to address these questions, I first provide an overview of Eve Ensler's The Vagina Monologues and the V-day movement. Then I summarize the existing critiques around The Vagina Monologues from both feminist scholars and activists. Later on, I introduce a local Chinese feminist group that created its own version of The Vagina Monologues. Finally, I offer a content-based analysis of a localized Chinese adaptation and discuss the significance of creating it. Ultimately, I argue that while Ensler's The Vagina Monologues have been globally circulated and discussed, the localized versions also merit scholarly attention. By being attuned to regional nuances and elements, the localized versions form closer connections with the local audience and thus are more effective for female empowerment.

\section{The Vagina Monologues: A Brief Overview}

The Vagina Monologues is an episodic play based on Eve Ensler's interviews with over 200 American women across all ages, races, types of employment, sexual orientations, and socioeconomic status. The play was first performed all by Eve Ensler herself in 1996 at the HERE Arts Center of New York (Note 9). "I was sure somebody would shoot me" (Note 10). That's how Ensler felt before her first performance, because according to her, "[24] years ago, no one said the word vagina" (Note 11). Ensler didn't get shot, instead, she "push[ed] through an invisible barrier, and breach[ed] a very deep taboo" (Note 12) in the tiny theatre in downtown Manhattan. It follows that the play ran Off-Broadway for five years in New York and then toured America (Note 13). In the present day, The Vagina Monologues continues to be produced in universities and colleges. The script has also been translated into over 50 languages and was performed in over 150 countries.

Shortly after The Vagina Monologues was launched, Ensler and a group of women in New York City started the V-day movement, which stands for Victory, Vagina, and Valentine. This global grassroots movement aims to end violence against women by raising awareness and gathering funds through performing The Vagina Monologues. Revenue made from the performances is invested in local anti-violence activities (Note 14). Since its beginning, the movement has raised over $\$ 100$ million. And there are over $5800 \mathrm{~V}$-day events annually (Note 15). The impact of The Vagina Monologues is extensive. It not only empowers women around the globe to fight stigmas, but also helps the victims of gender-based violence to have a space to express their voice.

\section{Literature Review: Critiques of the Vagina Monologues}

Despite its popularity, The Vagina Monologues has received numerous critiques from both scholars and activists. The critiques exist in both the US context and global context. Kim Q. Hall, a scholar of feminist theory and queer theory, raised three major criticisms of the play. Firstly, when discussing female genital mutilation and patriarchal violence, Ensler specifically focused on the experiences of women from the Third World, thus dismissing women from the western hemisphere from the discourse (Note 16). Moreover, Ensler's play conveys the message that the vagina serves a common bond between females and creates a sense of sisterhood, without taking into consideration people who are intersex. Both intersex genital mutilation and female genital mutilation are performed to correct unruly bodies and are acts of sexual violence. But intersex genital mutilation is rarely present in feminist conversations (Note 17). Lastly, as Ensler ends a play with a monologue extolling the power of reproduction, she ignores the issues that reproduction can also mean a lack of other choices such as affordable abortion (Note 18).

Christine M. Cooper, a scholar at the Women's Studies Research Center at Brandeis University, proposed a series of criticisms around the idea that the vagina is the essence of women. She argues that despite its "energizing and entertaining gesture" (Note 19), the fact that The Vagina Monologues binds women as subjective creatures to their body is a "dangerous association" (Note 20). In the west, women have been reduced to their bodies and their sex for centuries, which leads to their subordination in society. Moreover, bounding females to their body "underpins the argument for their liberation as versions of an essential same" (Note 21), for Ensler implies that the vagina is the essence of making one a woman. The play thus fails to "expand the cultural field bodily" (Note 22) and simply institutes new versions of old norms. In addition, the community of vaginas created by Ensler, while allowing female speakers to gain a greater voice, "flattens out... the diversity of experience within populations of women and across them too" (Note 23). For instance, it narrows the scope of violence against women down to only the ones that are sexualized. Even though Ensler envisions that taking vagina out of the closet "would release people to talk about other secrets" (Note 24). it also confines the stories of women to their personalized revelations and hinders us from discussing conditions that generate violence, such as poverty, shortage of clean air, or lack of child care (Note 25).

Sealing Cheng, a professor of anthropology and gender studies at the Chinese University of Hong Kong, devised a localized version of The Vagina Monologues in Hong Kong. She questions the "global vaginahood" (Note 26) of Ensler's script because "US women's experience and agenda" (Note 27) comes to define that of women in other 
parts of the world. She proposed that the Vaginal Central, where the original script was created and distributed, should recognize and identify "locally derived creative efforts." While many women around the globe are striving for the same cause of female empowerment and end of violence, they could have different experiences and strategies based on their location. Cheng also raises the possibility of turning her play from a monologue to a dialogue, inviting the audience to contribute their stories through workshops. Dialogue is a "common, healthy dynamic between all humans" (Note 28) and is "more attentive to difference, mutuality, and exchange" (Note 29). She forcefully concludes that "it is through dialogues, not monologues, that constructive transformation on a global scale could come about" (Note 30).

Many social activists have criticized the play as well, but mostly on different lights. Journalist Katherine Gillespie argues that The Vagina Monologues is not so relevant in the 21st-century feminism, for "a certain kind of women (straight, white, able-bodied) feels a little too empowered" (Note 31) and self-centered. Ashwini Hardikar from the University of Michigan-Ann Arbor makes a similar argument that the monologues that are supposed to represent women of color are almost all related to "violence, brutality, or coercion" (Note 32). But white, upper-class, western women - whom the majority of the monologues represent - are always portrayed to have positive sexual experiences. Hardikar believes that in Ensler's eyes, women of color are always victims and don't deserve to enjoy their vaginas.

However, Ensler herself forcefully responded to some criticisms, stating that "one play can't be everything" (Note 33). Regarding the most common criticism regarding the transgender community, Ensler explains that "transgender people have been performing [the play] for decades" (Note 34). She argues that while this play can not relate to every female's experience, it was as inclusive as possible and can still resonate with millions. As for the criticism that the play equates women to their vaginas, Ensler clarified that "the play has never been saying that the vagina is what defines the woman, it's just a play about vaginas" (Note 35). Ensler knows that women are more than their sexuality, but she created the piece in hope that sexual liberation can lead to greater freedom in all kinds of areas. Ensler is also very supportive of communities around the globe who create their own pieces if they didn't feel like the original script was relatable. "I celebrate people writing their own plays that unveil and undress sexuality and the dimensions of gender. I think there should be more and more and more plays written about that (Note 36)," she said.

China has echoed Ensler's idea by creating numerous versions of the localized Vagina Monologues. The localized adaptations have original content and themes that are relatively unique to the experiences of Chinese women. This uniqueness will be shown in the later analysis of the topics of virginity and sexual freedom.

\section{The Vagina Monologues in China}

The path of bringing The Vagina Monologues to China has been bumpy. Even though the challenge of the social norms made the play sensational in the US, it suffered from censorship and fierce backlash in China. It is not the sensitive content that "set off official censure" (Note 37), but simply the word "vagina", which is rarely printed in mainstream media.

In 2003, the show was performed in Chinese for the first time at Zhongshan University in Guangzhou Province. The feminist professor Xiaoming Ai translated Eve Ensler's original script and added in Chinese elements. However, a performance hosted by Shanghai Dramatic Arts Center was indefinitely postponed by the government in 2004, after the tickets were sold and 4 days before the designated date. The reason provided by the authority was that "the production was not yet mature" (Note 38). In the same year, a nonprofit and informal performance by the Today Arts Museum in Beijing was also halted midway. The play was finally performed in Shanghai Fudan University in 2004 (Note 39). In the fifteen years since, The Vagina Monologues has been adapted into many versions by a number of universities and NGOs. The list of universities where The Vagina Monologues has performed includes Peking University, Central China Normal University, Wuhan University, Xiamen University, and Capital Normal University. Xiaoming Ai believes that the Chinese version of The Vagina Monologues is not simply "a copy or transplantation of the original" (Note 40), but rather "a new theatrical creation that is both based on and speaks to Chinese women's experiences" (Note 41).

It has become impossible to calculate how many iterations have been created since 2003 for many reasons. Most adaptations didn't fit the copyright requirements by Eve Ensler. Moreover, most performances were hosted by universities and local organizations, and thus didn't produce any official documentation. Finally, the adaptations seem to gradually deviate from the original version because more and more Chinese elements and topics are added (Note 42).

I was able to acquire one of the Chinese adaptations of The Vagina Monologues, created by a Chinese non-profit feminist organization called The Vagina Project. The Vagina Project is a native feminist art project aiming to serve 
various sex/gender/sexuality communities in China. The organization hopes to raise individuals' gender awareness and calls for public respect for marginalized social groups through different programs, including interviews, dramas, seminars, and reading groups. The Vagina Project imitated Ensler's method of creation and interviewed over 60 Chinese women. After hearing their stories, the organization created its own script and updates it every year. The first one was finished and brought to stage in 2016, and the play has been performed 3 times, in 2016, 2018, and 2019 respectively. As a young feminist organization, The Vagina Project's performances had been fairly successful. In 2016, they were able to perform their play 5 times in Beijing, gathering over 450 audiences. With the cooperation of other feminist organizations, The Vagina Project circulated their performance to other cities, including Tianjin, Shanghai, Xiamen, etc. (Note 43). The version I acquired was updated and performed in 2018. It deviates from the topics of the original script by Ensler, mainly focusing on experiences unique to the Chinese culture. In what follows, I conduct a close reading of one of these monologues.

\section{5. "A Moist Spring"}

The monologue entitled "A Moist Spring" illustrates a woman's experiences of her "first times" and her reflections on these sexual experiences. The monologue invites viewers to think critically about the virginity complex, as well as other topics that are particularly pronounced in the Chinese context, such as lack of knowledge about female anatomy and the relation between virginity and responsibility.

The monologue starts out with two straightforward statements: "I have had many first times. I have slept with 33 people." Being able to lay out these facts shamelessly and blatantly implies that the author is unconventional and very open-minded, hinting that her experiences are likely to be the same.

The protagonist's first experience of penetration happened with another man who she reckoned was a "good guy" at first sight. The protagonist did not allow her partner to "enter" her until "after a long time." Her experience corresponds with a common practice among Chinese people. A 2019 study shows that out of nearly 10,000 Chinese adults, roughly 40 percent of them lose their virginity within one month of dating (Note 44). The same proportion is true for couples in the US 10 years ago, according to two studies in 2010 (Note 45). In a world where people are becoming more open-minded and sexually active at a younger age, China clearly shows a lag in the trend of sexual openness. This reinforces the conservative aspect of the protagonist, for in the Chinese culture, sex partners are not only about offering pleasure, but should also be someone who one respects and feels connected with.

China's lack of sexual openness can not only be demonstrated by the value of women's virginity, but also from men's obsessions with virgins. The virginity complex, "a preference among heterosexual men for female virgins," is a controversial topic with a profound history in China. For the majority of Chinese history, men have been the dominant sex and need to make sure that their wealth is passed on to their descendants. Asking their wives to be virgins before marriage thus became the only way to ensure their children are truly their own. It was not until the establishment of modern China that gender equality was promoted and western feminist ideas were introduced. However, the debate around the virginity complex is still prevalent in 21 st century China. Opinions are deeply divided across geographical locations and generations. In a study by Peking University, one of the most prestigious colleges in China, "the average age for Chinese people born after 1995 to have their first sexual experience is around 17," which is even earlier than the legal age for marriage. However, another official survey in 2010 shows that "about 80 percent of Chinese women in rural areas believe virginity is very important." While some people believe that chastity before marriage is simply outdated, others insist that virginity is one criterion for partner selection.

The protagonist's caution with her virginity and expectation for her "first time" was further demonstrated through the illustration of her first experience of penetration. She simply described her experience as "he moved a couple of times and went out." The simplicity of this process created a sharp contrast with the previous imagination of her first experience with sexual intercourse, which in her mind was a brave yet scary act like "jumping off of a one-hundred-floor building." While non-Chinese readers might reckon her analogy as overexaggerated, it can be quite relatable for many Chinese women. In China, sex education is often lacking or taught ambiguously, thus leading females to have various or even negative imagination about sex. For example, a high school textbook in Jiangxi Province went viral online for its definition of sex as "harmful, sinful, and [something that] would cause girls to lose respect for boys" (Note 46). Even worse, a study from 2015 shows "that only $10 \%$ of the nearly 20,000 university students from over 130 universities surveyed had received any sexuality education in primary school" (Note 47). Not receiving a comprehensive sex education can lead to negative health and safety outcomes, as well as inadequate sex awareness, as exemplified by the protagonist in the play.

The protagonist's lack of adequate sex education is more obviously revealed in the second section of her 
monologue, in which she describes her "second first time." When referring to her previous sexual experience, her usage of the phrase "my hymen was broken" clearly suggests a lack of knowledge about female anatomy. Her word choice clearly shows her innocence of the fact that the hymen is a thin layer of membrane situated at the opening of the vagina, partially closing the entrance. Therefore, the phrase "hymen is broken" is inherently and scientifically false. However, it can be reasonably conjectured that the playwrights purposefully chose such words to reflect the general misunderstanding of hymen among Chinese people. "The hymen was broken" is a very frequently-used phrase in Chinese when people converse about their first sexual experience. As an authoritative feminist organization, the playwrights should be very aware of the fact that this phrase is biologically incorrect and certainly would not use it in a scientific paper. The reason they chose to include this phrase in the monologue is twofold. Firstly, the word "broken" is inherently misleading because it implies that a woman is "broken", incomplete, or even used after a sexual experience. The playwrights are mocking this wrongful language by bringing the audience's attention to it in the play. Secondly, the protagonist compared "breaking the hymen" to a "ceremony" in her monologue. Even though the hymen barely holds any anatomical significance to women, for it can not be seen or felt, its sociological and cultural significance supersedes its biological existence. The playwrights juxtaposed the "broken hymen" and the "ceremony" to mock the phenomenon that a barely noticeable part of the female body, and the very idea of virginity, are awfully overrated in China.

In fact, there is still a prevalent perception among Chinese women that the hymen is a thin layer of skin that completely blocks the vagina, and would break at the one's first sexual intercourse (Note 48). This could be caused by the fact that the word "hymen" in Chinese is quite misleading, as it is translated as "virgin membrane", which can be perceived as a body part that represents something about a woman. This common misconception has grave implications. People associate breaking a hymen with bleeding, which allows them to imply that women should bleed when they lose their virginity. Throughout Chinese history, checking for blood on the blanket has remained as the most prevalent practice when checking the virginity of women. This method worked successfully in the past because girls got married and began sexual activities at a very young age (normally 14 or 15 years old). Their bodies are not fully grown at such a young age, thus their vaginas are more easily ruptured and bleed when penetration occurs (Note 49). The Chinese word "Jian Hong," meaning "seeing red", was even invented to specifically refer to this practice. The historical significance of this tradition is so profound that Chinese people are still unaware of the fact that bleeding is not necessarily associated with losing virginity for adult women. The effect of the myths around hymen can be even more extreme in China. In recent years, Chinese women are so conscious of the bleeding that some of them are opting for a surgical procedure called "hymen restoration." The surgery "returns the hymen to its condition before it was ruptured" (Note 50). It mainly targets women who are sexually active but have told their future husbands that they are virgins and a few others who have been victims of rape (Note 51). A cheaper and faster alternative to this surgery is "a Chinese-made artificial hymen that purports to create a physical sensation for the man and emit fake blood when ruptured" (Note 52). Even though no statistical evidence can be offered, sociologists and other experts believe that these methods to renew women's virginity have gained popularity (Note 53). In the case of this monologue, the protagonist's consciousness around her virginity speaks to the general lack of sex education in China, which is worth discussing because such issues are fairly popular in modern Chinese society.

After describing her experience of her "second first time", the protagonist discussed other topics around virginity in China - the responsibility that comes with sex. The protagonist claimed that she was glad because her sex partner "didn't feel guilty," unlike her first boyfriend who refused to "take her first time" even when she offered it. In fact, expressions such as "taking one's first time" and "losing one's virginity" implicitly conveys an idea that something in women is taken away by, in most cases, men, after her first sexual experience. This idea presses both Chinese men and women to believe that men are in debt to women after sex, for he has "taken away" her virginity, a precious quality deemed by many. Consequently, a viewpoint is developed in China that men should take responsibility for the woman he has had sex with. While there might be divergent opinions on what the responsibility should entail, a few common examples include marriage, emotional commitments, or providing information about his health status.

A more extreme case of a Chinese couple's disagreements on the relationship between sex and responsibility happened 8 years ago and was widely reported by mainstream media. The woman, Zhao Ru, was very sexually conservative and firmly believed that she should only have sex with one man that she would marry. Her boyfriend, Yan Fei, held an opposite viewpoint. After Zhao lost her virginity to Yan, she was so desperate and scared that she demanded a promise from her boyfriend to love her eternally. Otherwise, Yan would be required to pay her 100,000 RMB (approximately 14,000 dollars) as compensation. Due to job and family reasons, Yan broke up with Zhao. Yet he did not expect that this would infuriate Zhao, who chased after him, asking him to realize his promise. 
The dispute was settled by the local police and Yan paid 90,000 RMB (approximately 13,000 dollars) in compensation (Note 54).

While assigning an immense financial value to virginity is a very extreme case, there are still many Chinese women who are supportive of the opinion that they should be protected in a relationship, especially after the occurrence of sexual intercourse. The popularity of this belief then causes men to refrain from initiating sexual activities with women, especially virgins.

Clearly the protagonist and the man with whom she experienced her "second first time" belonged to the other camp, which stands behind the ideas of gender equality and sexual freedom. They both believed that no one should feel guilty for engaging in sexual activities, for they are both adults capable of making wise decisions. More importantly, they were not ashamed of their sexual desires, and are both supportive of a more liberal viewpoint - the separation of sex, emotional attachments, and commitments. The protagonist's sex partner clarified that "I just want you. I just want to have sex with you." Unlike Zhao from the story above, the protagonist felt "clear, excited, beautiful, and perfect."

Thus, the value of the localized version of The Vagina Monologues is revealed. The discussion of this regionally specific topic - virginity and responsibility — can alter the opinions of many female audiences and empower them to look at sex with a more open mind. The addition of elements that are widely prevalent in Chinese culture can increase the relatability of the play.

The protagonist's "third first time" was with a woman. In her depiction, she employed a sharp contrast between sexual experiences with women and that with men. The protagonist contended that most men "only wanted pleasure for themselves" and "didn't care if [she] was enjoying it" as well. In comparison, her sexual experience with the woman was mutually pleasurable and satisfying. More importantly, she felt loved in the experience because her partner was gentle, comfortable, and compatible. In addition, while the protagonist's male sex partners asked her to shave her pubes, the woman kissed them and appreciated them. The protagonist stated men "don't know a lot of things," but the woman was a better match for her because she understood her needs and feelings. Therefore, the protagonist used the word "love" only in the depiction of her experience with the woman, highlighting the difference between sex with a man and a woman.

In fact, both the original Vagina Monologues and the piece "A Moist Spring" seems to celebrate the sexual experience with women and degrade that with men. Only the original script does so on a more extreme scale. In the original version, the woman's sexual experiences with men and women are portrayed in very different lights, as mentioned in the literature review section. In the monologue "Hair," the woman's husband disliked her body hair and used it as an excuse for his derailment. "The Flood" illustrates the story of an elderly woman's lifelong shame for accidentally cumming on her date as a teenager. "My Village was my Vagina" was written in honor of thousands of victims in the rape camp in Bosnia and Kosovo. It haunts every audience with the brutal story of the soldier's sexual abuse and torture of women. In the piece "The Little Coochie Snorcher That Could," the protagonist was violently raped by her father's friend but was then saved by a woman who taught her how to satisfy herself. The only positive representation of male as a sex partner is in the piece "Because He Liked to Look at It," where the male character Bob made the protagonist fall in love and take pride in her vagina.

Throughout the protagonist's illustration of her three "first times," she is, in fact, mocking the very idea of virginity and the obsession with it in the current Chinese culture. The fact that she experienced virginity three times is an assertion that every sexual experience can be as valuable as the first one. The protagonist learned different lessons and increased her self-awareness through all of these sexual experiences, which is why she claims that she has three "first times." The monologue is named "A Moist Spring" for the same reason, for spring is a time of growth and becoming. For the protagonist, each one of the three experiences is a spring in the seasons of her life. Certainly, she believes virginity is valuable, but she finds every other sexual experience just as valuable. Virginity is not simply about an event occurring for the first time, it is a process of self-exploration, of coming to terms with one's desires, and of learning to love one's own body.

In conclusion, the monologue "A Moist Spring" is a successful localized iteration by discussing topics and cultural elements that are deeply rooted and widely prevalent in the Chinese culture. From the conservative attitude to sex, to a lack of sex education, and to the relationship between virginity and responsibility, the protagonist's stories are surely epitomes of the experiences of many Chinese audiences. When performance is hardly relatable, the theatrical effect is one-dimensional: the audience simply views the stories of others. However, when the performance resonates with the audience, another dimension is added to the theatrical experience: it becomes private. The audiences are not only viewing stories but are using them to mirror their own experiences. And this is the power of localized adaptations. It can build connections, inspire personal reflections, and lead to spiritual 
empowerment.

While the positive and inspiring sexual experiences portrayed by "The Moist Spring" can easily resonate with many Chinese audiences, there is a special group of women in China who have gone through a rather traumatic experience. They are the Chinese women who had been raped during World War II. Due to political and cultural reasons, their voices had been silenced and their stories had been hidden. Therefore, I created this monologue to reveal a dark side of Chinese history and to honor these women who have lived strong in the face of trauma.

\section{Acknowledgement}

I wish to acknowledge Professor Carly Thomsen and Grace Morrison for guiding me through the research process and encouraging me to create my own monologue. I also would like to thank Taolingeriler from the Vagina Project for providing me the script and introducing me to their amazing organization. Finally, I would like to thank my parents for supporting me throughout this journey.

\section{References}

Balwani, T. (2020). LUÜNA: Tackling Stigma, Shame \& Silence Around Periods Across Asia. Hive Life, July 11, 2019. Retrieved August 12, 2020, from https://hivelife.com/luuna-naturals-menstrual-health/

Braun, V., \& Celia, K. (2001). 'Snatch', 'Hole', or 'Honey-Pot'? Semantic Categories and the Problem of Nonspecificity in Female Genital Slang. The Journal of Sex Research, 38(2), 146-158. https://doi.org/10.1080/00224490109552082

Castro, M., \& Christine, C. (2020). The Vagina Monologues. Ke Kalahea. Last modified February $26,2018$. Retrieved July 14, 2020, from https://hilo.hawaii.edu/news/kekalahea/the-vagina-monologues-2018

Center for Women and Gender Equity. (2020). V-Day: Until the Violence Stops. Saint Marry's College of $\begin{array}{lllll}\text { California. } & \text { Retrieved July } & 16, & 2020, & \text { from }\end{array}$ https://www.stmarys-ca.edu/center-for-women-gender-equity/events-in-the-cwge/v-day-until-the-violence-s tops-2020

Chart. Statista. (2020). Share of young adult respondents who waited before losing their virginity in China as of July 2019 by relationship duration. August 2019. Retrieved July 23, 2020, from https://www.statista.com/statistics/1102733/china-how-long-young-people-wait-to-have-their-first-time-sex -after-knowing-each-other/

Cheng, S. (2009). Questioning Global Vaginahood: Reflections from Adapting The Vagina Monologues in Hong Kong. Feminist Review, 92, 19-35. https://doi.org/10.1057/fr.2009.3

China Daily. (2020). Stage Drama 'Vagina Monologues'Banned in China. February 8, 2004. Retrieved August 12, 2020, from http://www.chinadaily.com.cn/english/doc/2004-02/08/content_304238.htm

Cooper, C. M. (2007). Worrying about Vaginas: Feminism and Eve Ensler's The Vagina Monologues. Signs, 32(3), 727-758. https://doi.org/10.1086/499084

CRI Online. (2020). Chinese Comfort Women Are Sick for Life, A Third of Them Can Not Reproduce. June 21, 2005. Retrieved August 12, 2020, from http://news.cri.cn/gb/1321/2005/06/21/1327@592189.htm

Ensler, E. (2020). Even with a Misogynist Predator-in-chief, We Will Not Be Silenced. The Guardian, August 23, 2017. Retrieved July $\quad 14, \quad 2020, \quad$ from https://www.theguardian.com/commentisfree/2017/aug/24/20-years-after-the-vagina-monologues-breakingsilence-is-still-a-radical-act

Gillespie, K. (2020). Do We Still Need 'The Vagina Monologues'? Vice, October 3, 2017. Retrieved July 8, 2020 , from https://www.vice.com/en_nz/article/j5gk8p/is-the-vagina-monologues-still-woke

Hall, K. Q. (2005). Queerness, Disability, and The Vagina Monologues. Hypatia, 20(1), 99-119. https://doi.org/10.1353/hyp.2005.0010

Hardikar, A. (2020). How Students Are Adding Diversity to Eve Ensler's Play. Generation Progress, February 13, 2007. Retrieved July 18, 2020, from https://genprogress.org/not-my-vagina-monologue/

Heiser, C. (2020). This Is How Women Feel About Saying the Word 'Vagina': Watch the Video. Women's Health, $\begin{array}{llllll}\text { August 21, 2015. Retrieved fuly } & \text { from }\end{array}$ https:/www.womenshealthmag.com/health/a19984644/the-word-vagina/

Huang, Y. M. (2017). Why Is China Still Obsessed with Virginity? Six Tone. Retrieved May 26, 2017, from https://www.sixthtone.com/news/1000261/why-is-china-still-obsessed-with-virginity\%3F 
Jaffe, G. (2020). Performing the Vagina Monologues in China. The Atlantic (Beijing, China), November 29, 2013. Retrieved July $\quad 8, \quad 2020, \quad$ from https://www.theatlantic.com/china/archive/2013/11/performing-em-the-vagina-monologues-em-in-china/28 $1924 /$

Jin, Z. X. (2020). Do Chinese Men Still Have A 'Virginity Complex'? China Global Television Network, June 18, 2017. Retrieved July 23, 2020, from https://news.cgtn.com/news/3d51544f304d444e/share_p.html

Kahn, J. (2020). Beijing Journal; Offended by the V-Word, China Mutes 'Monologues'. New York Times, February 13, 2004. Retrieved July 27, 2020, from https://www.nytimes.com/2004/02/13/world/beijing-journal-offended-by-the-v-word-china-mutes-monolog ues.html

Laughland, O. (2020). Vagina Monologues Playwright: 'It Never Said a Woman Is Someone with a Vagina'. The Guardian (New York, US), January 16, 2015. Retrieved July 18, 2020, from https://www.theguardian.com/world/2015/jan/16/vagina-monologues-eve-ensler-rejects-mount-holyoke-coll ege-claims-reductionist-exclusive

Lin-Liu, J. (2004). 'Vagina Monologues' Performed on Shanghai Campus. The Chronicle of Higher Education, Retrieved May 28, from https://libproxy.nmhschool.org:2408/apps/doc/A147104622/AONE?u=mlin_w_nthfield\&sid=AONE\&xid= $41527 \mathrm{~d} 0 \mathrm{e}$

Ma, L. (2020). 'The Vagina Monologues' Ten Years in China. Helan Online, July 17, 2013. Retrieved July 21, 2020, from https://helanonline.cn/archive/article/5131

Mai, J. (2020). Chinese former 'comfort women', aged 94 and 90, break silence about brutal treatment by Japanese soldiers. South China Morning Post, July 23, 2017. Retrieved August 5, 2020, from https://www.scmp.com/news/china/society/article/2156498/chinese-former-comfort-women-aged-94-and-9 0 -break-silence-about

Pin Lue Library. (2020). "The Vagina Project" 2017 Fall Recruitment. Last modified September 2, 2017. Retrieved July 27, 2020, from http://www.pinlue.com/article/2017/09/0220/424395307140.html

Richburg, K. B. (2020). Knowing cultural view of virginity, Chinese women try surgical restoration. Washington Post (Beijing, China), August 17, 2010. Retrieved July 27, 2020, from https://wunrn.com/2010/08/china-value-of-virginity-hymen-restoration-surgery/

Rodriguez, S. B., \& Toby, L. S. (2012). The Organ-That-Must-Not-Be-Named: Female Genitals and Generalized References. The Hastings Center Report, 42(3), 19-21. https://doi.org/10.1002/hast.35

Sassler, S., Fenaba, R. A., \& Daniel, T. L. (2012). The Tempo of Sexual Activity and Later Relationship Quality. Journal of Marriage and Family, 74(4), 708-725. https://doi.org/10.1111/j.1741-3737.2012.00996.x

Tang, L. (2020). Chinese Vagina Monologues and Beyond. The Theatre Times, April 19, 2018. Retrieved July 8 , 2020, from https://thetheatretimes.com/chinese-vagina-monologues-beyond/

Tencent. (2020). The Attitude of a Female College Student: Responsibility Comes with Sex. February 28, 2012. Retrieved July 27, 2020, from https://fashion.qq.com/a/20120228/000007.htm.

UNESCO. (2020). It Is Time to Face the Facts: Young People in China Ask More from Comprehensive Sexuality Education. Last modified September 26, 2019. Retrieved July 23, 2020, from https://en.unesco.org/news/it-time-face-facts-young-people-china-ask-more-comprehensive-sexuality-educa tion

V-day. (2020a). Who, What \& How. Retrieved July 14, 2020, from https://www.vday.org/about/who-what-how.html

V-day. (2020b). Why V-Day Started. Retrieved July 14, 2020, from https://www.vday.org/about/why-vday-started.html.

Wang, Q. (2018). Young Feminist Activists in Present-Day China. China Perspectives, 3(114), 59-68. https://doi.org/10.4000/chinaperspectives. 8165

Whisnant, R. (2017). Feminist Perspectives on Rape. In N. Z. Edward (Ed.), Stanford Encyclopedia of Philosophy (Fall 2017 ed.). Metaphysics Research Lab, Stanford University, 2017. Last modified June 21, 2017. Retrieved August 12, 2020, from https://plato.stanford.edu/entries/feminism-rape/ 
Xin, J. B. (2020). Two "Comfort Women" Survivors Found in YueYang: Surpassing Time and Witness the History. March 13, 2019. Retrieved August 12, 2020, from https://baijiahao.baidu.com/s?id=1627870423816650273\&wfr=spider\&for=pc

Yang, Y. Z. (2020). China made 85 billion sanitary pads last year, and not one tampon. Here's why. Los Angelos Times, March 18, 2016. Retrieved August 12, 2020, from https://www.latimes.com/world/asia/la-fg-china-tampons-20160318-story.html

Ziye. (2020). The Hymen That Has Been Misunderstood for Thousands of Years. Zhihu. Last modified July 26, 2019. Retrieved July 26, 2020, from https://zhuanlan.zhihu.com/p/46736102

\section{Notes}

Note 1. Virginia Braun \& Celia Kitzinger. (2001). 'Snatch', 'Hole', or 'Honey-Pot'? Semantic Categories and the Problem of Nonspecificity in Female Genital Slang. The Journal of Sex Research, 38(2), 156. Retrieved from http://libproxy.nmhschool.org:2107/stable/3813705

Note 2. Braun \& Kitzinger. “'Snatch', 'Hole'," p. 157.

Note 3. Sarah, B. R., \& Toby, L. S. (2012). The Organ-That-Must-Not-Be-Named: Female Genitals and Generalized References. The Hastings Center Report, 42(3), 19. Retrieved from http://libproxy.nmhschool.org:2107/stable/23883186

Note 4. Christina, H. (2020). This Is How Women Feel About Saying the Word 'Vagina': Watch the Video. Women's Health, August 21, 2015. Retrieved July 14, 2020, from https://www.womenshealthmag.com/health/a19984644/the-word-vagina/

Note 5. Tanya, B. (2020). LUÜNA: Tackling Stigma, Shame \& Silence Around Periods Across Asia. Hive Life, July 11, 2019. Retrieved August 12, 2020, from https://hivelife.com/luuna-naturals-menstrual-health/

Note 6. Yang, Y. Z. (2020). China made 85 billion sanitary pads last year, and not one tampon. Here's why. Los Angelos Times, March 18, 2016. Retrieved August 12, 2020, from https://www.latimes.com/world/asia/la-fg-china-tampons-20160318-story.html

Note 7. China Daily. (2020). Stage drama 'Vagina Monologues' banned in China. February 8, 2004. Retrieved August 12, 2020, from http://www.chinadaily.com.cn/english/doc/2004-02/08/content_304238.htm

Note 8. Rebecca, W. (2020). Feminist Perspectives on Rape. In N. Z. Edward (Ed.), Stanford Encyclopedia of Philosophy (Fall 2017 ed.). Metaphysics Research Lab, Stanford University, 2017. Last modified June 21, 2017. Retrieved August 12, 2020, https://plato.stanford.edu/entries/feminism-rape/

Note 9. Maria Christine, C. C. (2020). The Vagina Monologues. Ke Kalahea, last modified February 26, 2018. Retrieved July 14, 2020, from https://hilo.hawaii.edu/news/kekalahea/the-vagina-monologues-2018

Note 10. Eve, E. (2020). Even with a misogynist predator-in-chief, we will not be silenced. The Guardian, August 23, 2017. Retrieved July 14, 2020, from https://www.theguardian.com/commentisfree/2017/aug/24/20-years-after-the-vagina-monologues-breaking-silen ce-is-still-a-radical-act

Note 11. Ensler, Even with.

Note 12. Ensler, Even with.

Note 13. V-day. (2020). Why V-Day Started. Retrieved July 14, 2020, from https://www.vday.org/about/why-vday-started.html

Note 14. V-day. (2020). Who, What \& How. Retrieved July 14, 2020, from https://www.vday.org/about/who-what-how.html

Note 15. Center for Women and Gender Equity. (2020). V-Day: Until the Violence Stops. Saint Marry's College of California. Retrieved July 16, 2020, from https://www.stmarys-ca.edu/center-for-women-gender-equity/events-in-the-cwge/v-day-until-the-violence-stops2020

Note 16. Kim, Q. H. (2005). Queerness, Disability, and the Vagina Monologues. Hypatia, 20(1), 102. Retrieved from http://libproxy.nmhschool.org:2107/stable/3810845

Note 17. Hall. Queerness, Disability (p. 104). 
Note 18. Hall. Queerness, Disability (p. 108).

Note 19. Christine, M. C. (2007). Worrying about Vaginas: Feminism and Eve Ensler's The Vagina Monologues. Signs, 32(3). 733. https://doi.org/10.1086/499084.

Note 20. Cooper. Worrying about (p. 734).

Note 21. Cooper. Worrying about (p. 737).

Note 22. Cooper. Worrying about (p. 738).

Note 23. Cooper. Worrying about (p. 738).

Note 24. Cooper. Worrying about (p. 744).

Note 25. Cooper. Worrying about (p. 744).

Note 26. Sealing, C. (2009). "Questioning Global Vaginahood: Reflections from Adapting The Vagina Monologues in Hong Kong. Feminist Review, 92, 19. Retrieved from http://libproxy.nmhschool.org:2107/stable/40664030.

Note 27. Cheng. Questioning Global (p. 19).

Note 28. Cheng. Questioning Global (p. 32).

Note 29. Cheng. Questioning Global (p. 32).

Note 30. Cheng. Questioning Global (p. 33).

Note 31. Katherine, G. (2020). Do We Still Need 'The Vagina Monologues'? Vice, October 3, 2017. Retrieved July 8, 2020, from https://www.vice.com/en_nz/article/j5gk8p/is-the-vagina-monologues-still-woke

Note 32. Ashwini, H. (2020). How students are adding diversity to Eve Ensler's play. Generation Progress, February 13, 2007. Retrieved July 18, 2020, from https://genprogress.org/not-my-vagina-monologue/

Note 33. Gillespie. Do We Still.

Note 34. Gillespie. Do We Still.

Note 35. Gillespie. Do We Still.

Note 36. Oliver, La. (2020). Vagina Monologues playwright: 'It never said a woman is someone with a vagina'. The Guardian (New York, US), January 16, 2015. Retrieved July 18, 2020, from https://www.theguardian.com/world/2015/jan/16/vagina-monologues-eve-ensler-rejects-mount-holyoke-collegeclaims-reductionist-exclusive

Note 37. Joseph, K. (2004). Beijing Journal; Offended by the V-Word, China Mutes 'Monologues'. New York Times, February 13, 2004. Retrieved July 27, 2020, from https://www.nytimes.com/2004/02/13/world/beijing-journal-offended-by-the-v-word-china-mutes-monologues.h tml

Note 38. Kahn. Beijing Journal.

Note 39. Lei, M. (2020). The Vagina Monologues' Ten Years in China. Helan Online, July 17, 2013. Retrieved July 21, 2020, from https://helanonline.cn/archive/article/5131

Note 40. Wang, Q. (2018). Young Feminist Activists in Present-Day China. China Perspectives, 3(114), 63. https://doi.org/10.2307/26531932

Note 41. Wang. Young Feminist (p. 63).

Note 42. Ma, The Vagina Monologues' Ten Years in China.

Note 43. "The Vagina Project" 2017 Fall Recruitment. Pin Lue Library, last modified September 2, 2017. Retrieved July 27, 2020, from http://www.pinlue.com/article/2017/09/0220/424395307140.html

Note 44. Share of young adult respondents who waited before losing their virginity in China as of July 2019, by relationship duration. chart, Statista, August 2019. Retrieved July 23, 2020, from https://www.statista.com/statistics/1102733/china-how-long-young-people-wait-to-have-their-first-time-sex-after -knowing-each-other/

Note 45. Sharon, S., Fenaba, R. A., \& Daniel, T. L. (2012). The Tempo of Sexual Activity and Later Relationship Quality. Journal of Marriage and Family. 74(4), 709. Retrieved from 
http://ibproxy.nmhschool.org:2107/stable/41678751

Note 46. Jin. Do Chinese.

Note 47. UNESCO. It is time to face the facts: Young people in China ask more from comprehensive sexuality education. Last modified September 26, 2019. Retrieved July 23, 2020, from https://en.unesco.org/news/it-time-face-facts-young-people-china-ask-more-comprehensive-sexuality-education

Note 48. Ziye. The Hymen That Has Been Misunderstood for Thousands of Years. Zhihu, last modified July 26, 2019. Retrieved July 26, 2020, from https://zhuanlan.zhihu.com/p/46736102

Note 49. Ziye. The Hymen That Has Been Misunderstood for Thousands of Years. Zhihu.

Note 50. Keith, B. R. (2020). Knowing cultural view of virginity, Chinese women try surgical restoration. Washington Post (Beijing, China), August 17, 2010. Retrieved July 27, 2020, from https://wunrn.com/2010/08/china-value-of-virginity-hymen-restoration-surgery/

Note 51. Richburg. Knowing cultural.

Note 52. Richburg. Knowing cultural.

Note 53. Richburg. Knowing cultural.

Note 54. The Attitude of a Female College Student: Responsibility Comes with Sex. Tencent, February 28, 2012. Retrieved July 27, 2020, from https://fashion.qq.com/a/20120228/000007.htm.

\section{Copyrights}

Copyright for this article is retained by the author, with first publication rights granted to the journal.

This is an open-access article distributed under the terms and conditions of the Creative Commons Attribution license (http://creativecommons.org/licenses/by/4.0/). 